NOTE

\title{
Diet-dependent UVAR and UVBR resistance in the high shore harpacticoid copepod Tigriopus brevicornis
}

\author{
John Davenport ${ }^{1, *}{ }^{\text {, Aine Healy }}{ }^{1}$, Noreen Casey $^{2}$, James J. A. Heffron ${ }^{2}$ \\ ${ }^{1}$ Department of Zoology \& Animal Ecology and Environmental Research Institute, and ${ }^{2}$ Department of Biochemistry, \\ University College Cork, Lee Maltings, Prospect Row, Cork, Ireland
}

\begin{abstract}
This study tested the hypotheses (1) that the upper shore rock pool harpacticoid copepod Tigriopus brevicornis is protected against ultra-violet radiation (UVR) by the orange pigment astaxanthin, and (2) that astaxanthin levels would be greater in summer than winter. Wild orange copepods lost their pigment and became white if fed on yeast in the dark; their colour was restored when they were fed microalgae. White T. brevicornis were significantly more susceptible to UVR than wild or restored orange T. brevicornis. At similar intensities of radiation, copepods showed duration of survival in the order UVAR $>$ UVBR. Astaxanthin protected $T$. brevicornis against UVAR and UVBR, with the degree of effectiveness of protection being in the order UVAR $>$ UVBR. There was no significant increase in astaxanthin levels during summer in $T$. brevicornis collected from 3 different shores. It is suggested that UVAR protection by astaxanthin largely follows from its effectiveness as an antioxidant, and that there are adequate plant resources available to maintain astaxanthin levels in T. brevicornis throughout the year.
\end{abstract}

KEY WORDS: Astaxanthin · Ultra-violet radiation · Tigriopus · Antioxidant

Resale or republication not permitted without written consent of the publisher

\section{INTRODUCTION}

The marine harpacticoid copepod genus Tigriopus Norman is cosmopolitan in both hemispheres and highly speciose. However, all species are found in essentially the same habitat: upper shore rock pools above mean tide level. Pools are often no more than a few millimetres in depth, so provide little protection against a variety of environmental stresses including exposure to high visible light and ultra-violet radiation (UVR) levels.

Tigriopus spp. are all bright orange in colour, the pigment being astaxanthin (Goodwin \& Srisukh 1949). In larger crustaceans (e.g. Cancer pagurus) astaxanthin is found to be entirely stored within the integument (Goodwin \& Srisukh 1949). This is probably also true in Tigriopus spp., although their small size has inhibited confirmatory studies so far. Dethier (1980), who studied T. californicus (Baker), suggested that the pigmentation had adaptive value, protecting the animals against damaging light intensities. In support of this hypothesis, she cited convincing evidence of selective benefit derived from limnetic copepods that possessed similar pigments (Hairston 1979). This topic has recently been revisited by Chalker-Scott (1995), who found that $T$. californicus was more tolerant of UVBR (290 to $320 \mathrm{~nm}$ ) than the planktonic calanoid copepod Acartia clausii (Giesbrecht). Although strongly suggestive of a UVR protectant role, these observations cannot be proof-positive, as the data were collected from different genera inhabiting different habitats. The orange colour makes Tigriopus conspicuous and 
led Dethier (1980) to conduct experiments which indicate that $T$. californicus is excluded from pools lower on the shore by predation (mainly by small fish, but also by sea anemones).

During pilot culture experiments, Davenport et al. (1997) discovered that NE European Tigriopus brevicornis (Müller) fed exclusively on brewers' yeast lost their colour, becoming white in appearance. Feeding the copepods on the microalgae Isochrysis sp. and Tetraselmis sp. could restore colour. This finding opened up the possibility of the quantitative and unequivocal study of the value of astaxanthin to UVscreening in this species.

The present study was designed to compare the responses of 'wild orange', 'white' and 'restored orange' Tigriopus brevicornis to UVAR and UVBR. The basic hypothesis was that copepods without astaxanthin would show increased sensitivity to UVR. A second hypothesis, that $T$. brevicornis would contain more pigment in summer than winter because of greater availability of plant food material, was also tested.

\section{MATERIALS AND METHODS}

Specimens of Tigriopus brevicornis for most studies reported here were collected from a few closely located pools on a rocky shore at Myrtleville, Cork Harbour, Ireland, using fine mesh sieves. Specimens needed for comparisons of winter and summer pigment levels were collected from 3 separate rocky shores in County Cork, Ireland (Myrtleville, Bullen's Bay and Garretstown), to minimize problems of confounding site and season (Underwood 1997). Specimens taken from the field ('wild orange') were held in seawater $(34 \%)$ at room temperature with access to a mixed diet of Enteromorpha sp. collected from their rock pools, supplemented ad libitum with the microalgae Tetraselmis sp. To obtain 'white' copepods, cultures of hundreds of wild orange $T$. brevicornis were set up in filtered seawater (without Enteromorpha sp.) in the dark, to which yeast solution (dried bakers' yeast in seawater) was added. Copepods became white to the naked eye in about $2 \mathrm{wk}$ and were pipetted out of the cultures for use in experiments. 'Restored orange' copepods were obtained by feeding cultures of white copepods for about 2 wk on Tetraselmis sp.

Two $6 \mathrm{~W}$ aged UVR lamps were available (UVAR $365 \mathrm{nM}$, UVBR $312 \mathrm{nM}$; Vilber Lourmat lamps, BDH Supplies). It should be noted that the Vilber UVBR lamp has no output below $290 \mathrm{~nm}$ (confirmed by the manufacturer's spectral curves), so it is not necessary to add cellulose acetate sheeting to exclude UVCR (cf. Zagarese et al. 1997). To expose Tigriopus brevi- cornis to UVR, 20 animals at a time were placed in a petri dish filled to a depth of $8 \mathrm{~mm}$ with seawater. The petri dish was mounted beneath the UV lamp being used, which was positioned $62 \mathrm{~mm}$ from the seawater surface. Temperature of seawater was 23 to $24^{\circ} \mathrm{C}$ throughout the experiment (room temperature was held at $22^{\circ} \mathrm{C}$ ). These temperatures are well within the range of the species' natural exposure $\left(>30^{\circ} \mathrm{C}\right.$ on warm days). A UVR meter (Model UVX Radiometer, Ultra-Violet Products) was employed to measure (in triplicate) the radiation intensity at that distance from the lamp being used (Table 1). Intensities of the different lamps were similar for each wavelength (within $18 \%$ of each other). Field UVR measurements were made using the same meter at noon on cloudy and bright summer days for comparative purposes.

To determine UVR resistance, separate batches of 20 animals were each exposed beneath a lamp for a fixed period of time and scored for mortality by inspection beneath a binocular microscope. Exposure times were chosen pragmatically (i.e. in the light of results obtained) until a minimum of 3 batches of copepods exposed for different periods of time had exhibited mortalities greater than $0 \%$ and less than $100 \%$. During this process, times at which mortality was 0 or $100 \%$ were also obtained. Probit analysis was employed to determine median lethal exposure times and $95 \%$ confidence intervals (Finney 1971).

First, wild orange copepods were exposed to UVAR and UVBR and median lethal times established for each type of radiation. Next, these experiments were repeated for white and restored orange copepods.

The pigment extraction method employed was based on that described by Goodwin et al. (1949), with the exception that methanol was used as a solvent instead of acetone. For each measurement, 100 Tigriopus brevicornis were taken from culture (wild orange, white or restored orange) by Pasteur pipette. They were transferred to a test tube containing fresh seawater. The volume of water in the tube was reduced and the $T$. brevicornis transferred to a $1.5 \mathrm{ml}$ pre-

Table 1. Tigriopus brevicornis. Experimental and field UVR measurements

\begin{tabular}{|lcc|}
\hline & $\begin{array}{c}\mathrm{UVAR} \\
\left(\mathrm{mW} \mathrm{cm}^{-2}\right)\end{array}$ & $\begin{array}{c}\mathrm{UVBR} \\
\left(\mathrm{mW} \mathrm{cm}^{-2}\right)\end{array}$ \\
\hline $\begin{array}{l}\text { (a) Mean experimental lamp } \\
\text { intensities (at water surface) }\end{array}$ & 1.17 & 1.38 \\
$\begin{array}{l}\text { (b) Cloudy summer noon } \\
\text { conditions }\end{array}$ & 1.67 & 0.746 \\
$\begin{array}{l}\text { (c) Cloudless summer noon } \\
\text { conditions }\end{array}$ & 2.36 & 1.001 \\
\hline
\end{tabular}


Table 2. Tigriopus brevicornis. Results of UVR exposure trials. MLT = median lethal time (h), ucl = upper confidence limit $(95 \%$; h), lcl = lower confidence limit $(95 \%$; h) (derived by Probit Analysis, Finney 1971)

\begin{tabular}{|c|c|c|c|c|c|c|}
\hline \multirow{2}{*}{$\begin{array}{l}\text { Copepod } \\
\text { category }\end{array}$} & \multicolumn{3}{|c|}{ UVAR } & \multicolumn{3}{|c|}{-UVBR } \\
\hline & MLT & ucl & lcl & MLT & $\mathrm{ucl}$ & lcl \\
\hline Wild orange & $>96$ & - & - & 4.08 & 4.29 & 3.83 \\
\hline White & 21.1 & 21.9 & 21.0 & 1.33 & 1.38 & 1.22 \\
\hline Restored orange & $>96$ & - & - & 4.57 & 4.42 & 4.25 \\
\hline
\end{tabular}

\section{RESULTS}

Field measurements of peak noon UVR intensity at the surface of Tigriopus brevicornis pools are shown in Table 1. Taken with the lamp intensity measurements, these indicate that levels of UVAR and UVBR used in experiments were environmentally realistic (though sustained for longer periods than would occur in nature). Results of UV-exposure trials are

weighed Eppendorf tube. Seawater was removed using a small syringe and 23G needle. The copepods were rinsed 3 times in distilled water to remove all seawater. After rinsing, the Eppendorf tubes containing the animals were spun at $13000 \mathrm{rpm}$ at room temperature using an Eppendorf centrifuge (model 5417C) to form a pellet; this was dried in a Savant DNA speed vac 100 for 15 min on low heat. The Eppendorf tubes containing dried pellets were re-weighed to establish the dry weight of the animals. A total of $500 \mu \mathrm{l}$ highpressure liquid chromatography (HPLC) grade methanol was added to the dried pellet to extract pigment. The Eppendorf tubes containing methanol and animals were sonicated (using a Branson 200 ultrasonic cleaner) for 2 min to speed up the extraction process and to disrupt the copepods' tissues. The tubes were spun again in the Eppendorf centrifuge to sediment debris and the supernatant containing the pigment was removed using a fine needle and syringe, transferred to a sample tube and diluted to $1 \mathrm{ml}$ for HPLC analysis.

Astaxanthin in the samples was separated by HPLC using a Varian Pro Star HPLC equipped with a diode array detector and autosampler. The diode array detector had greater sensitivity and stability than the regular variable wavelength detector. The column used was a Supelcosil LC-18 $(25 \mathrm{~mm} \times 4.6 \mathrm{~mm} \times$ $5 \mu \mathrm{M}$; Supelco, Sigma-Aldrich). Astaxanthin was eluted using methanol as mobile phase over a $30 \mathrm{~min}$ period. The mobile phase was initially degassed with helium. The detection wavelength was $474 \mathrm{~nm}$. Standard astaxanthin solutions were made up in methanol. Pure astaxanthin was obtained from Sigma-Aldrich. The efficiency of pigment extraction from the pellet was checked by adding standard astaxanthin to the pellet before extraction at a concentration similar to that in the pellets alone. The recovery of the standard was $93 \pm 4.0 \%$ (mean \pm standard deviation for 5 separate extractions). The precision of the measurement of astaxanthin, expressed as a coefficient of variation, was 3.8\%, based on 5 separate measurements on an extract containing $4.4 \mu \mathrm{g}$ astaxanthin $\mathrm{ml}^{-1}$. shown in Table 2. First, from the data for white copepods it is evident that tolerances of different UVwavelengths (applied at similar intensities) differ markedly. Median lethal time (MLT) for UVAR was 16 times greater than for UVBR. Second, the data for white copepods also show that UVAR is lethal to them $(\mathrm{MLT}=21.1 \mathrm{~h})$ at realistic environmental intensities.

In contrast, both wild orange and restored orange Tigriopus brevicornis survived UVAR exposure indefinitely (>96 $\mathrm{h},>4.5$ times as long as white copepods), indicating a protective role for astaxanthin against UVAR. In the case of UVBR exposure, wild orange copepods survived 3.1 times as long as white copepods ( $p<0.05$; non-overlapping 95\% confidence intervals derived from Probit analysis), while restored orange copepods survived for rather longer (3.4 times white copepod survival time), though the difference in MLT between wild and restored orange animals was not statistically significant ( $p>0.05$; overlapping $95 \%$ confidence intervals derived from Probit analysis). This demonstrates a protective role for astaxanthin against UVBR.

Table 3 shows the pigment levels of the experimental copepods. No astaxanthin was detectable in white copepods, while restored orange copepods contained significantly more (ANOVA: $\mathrm{p}<0.001)$ astaxanthin $(2.1$ times) than wild orange animals. These data confirm that diet controls astaxanthin levels, and that white animals have negligible astaxanthin content. The higher level of astaxanthin in restored orange cope-

Table 3. Tigriopus brevicornis. Astaxanthin concentrations $(\mathrm{n}=$ 3 ; each replicate represents 100 animals) in T. brevicornis collected from Myrtleville, County Cork, in summer (the data correspond with UVR exposure data of Table 2). nd = not detected

\begin{tabular}{|c|c|}
\hline $\begin{array}{l}\text { Copepod } \\
\text { category }\end{array}$ & $\begin{array}{l}\text { Astaxanthin content } \\
\left(\mu \mathrm{g} \text { mg dry } \mathrm{wt}^{-1}\right) \\
(\text { mean } \pm \mathrm{SD})\end{array}$ \\
\hline Wild orange & $4.86 \pm 0.29$ \\
\hline White & nd \\
\hline Restored orange & $10.35 \pm 0.10$ \\
\hline
\end{tabular}


Table 4. Tigriopus brevicornis. Comparison of astaxanthin concentrations in $T$. brevicornis from 3 different shores during summer and winter

\begin{tabular}{|lc|}
\hline Site & $\begin{array}{r}\text { Astaxanthin content } \\
\left(\mu g \text { mg dry wt }{ }^{-1}\right) \\
(\text { mean } \pm \text { SD })\end{array}$ \\
\hline Summer & \\
Myrtleville & $4.86 \pm 0.29$ \\
Bullen's Bay & $4.64 \pm 2.10$ \\
Garretstown & $8.70 \pm 2.73$ \\
Winter & \\
Myrtleville & $7.57 \pm 0.51$ \\
Bullen's Bay & $5.15 \pm 0.44$ \\
Garretstown & $7.74 \pm 0.86$ \\
\hline
\end{tabular}

pods presumably explains the better tolerance of UVBR (Table 2).

Table 4 shows the results of astaxanthin measurements upon Tigriopus brevicornis from different shores at different seasons. Only the Myrtleville shore showed a significant difference between winter and summer astaxanthin levels (ANOVA: $p<0.01$ ), and in this case the winter value was higher. Overall there was no significant effect of site or season (ANOVA: p > 0.05). The hypothesis of higher astaxanthin levels in summer is therefore not supported.

\section{DISCUSSION}

The results clearly demonstrate that astaxanthin protects Tigriopus brevicornis against all UVAR and UVBR, with protection being proportionally greater for UVAR. This has not been demonstrated in any other study on any other aquatic organism. Most investigations on pelagic and planktonic organisms (e.g. Browman et al. 2000) have been concentrated on UVBR effects because of enhanced UVB resulting from stratospheric ozone depletion in temperate and arctic latitudes (Kerr \& McElroy 1993). UVBR is known to induce biomolecular damage (particularly to DNA) directly. The UVAR component of solar radiation is now accepted to be a powerful inducer of oxidative stress, by causing the formation of reactive oxygen species (Pouzand \& Tyrell 1999).

Astaxanthin is a carotene pigment, shown to have much superior anti-oxidant properties to other carotenes in a number of in vitro studies (e.g. Terao 1989, Miki 1991, Palozza \& Krinsky 1992, Lawlor \& O'Brien 1995). It has about 10 times the effectiveness of beta-carotene, and is over 100 times as strong an antioxidant as vitamin E (Tso \& Lam 1996). Whether it directly screens against UVR is less clear; Gorton et al. (2001) recently studied the high altitude snow alga
Chlamydomonas nivalis and found that astaxanthin almost totally prevented blue light from reaching the chloroplast, but that 'other unknown absorbers' screened out UVR. Clearly more studies are needed to elucidate the protection mechanism further.

Animals cannot synthesize astaxanthin de novo; it has to be taken in from a plant diet. Tigriopus brevicornis lives in pools that have 3 potential sources of plant material: (1) macroalgae, particularly Enteromorpha spp. (but note that pools often contain no macroalgae, so T. brevicornis cannot rely on Enteromorpha spp. shading), (2) phytoplankton, and (3) benthic or epiphytic diatoms. It is evident from this study that sufficient resources are available to support high astaxanthin levels throughout the year. T. brevicornis populations in pools are smaller in winter than in summer (McAllen 1998), so it may be that the inevitable decline in primary production in winter in the high shore pools is offset by reduced grazing pressure. McAllen (1998) also found shifting proportions of males, females and ovigerous females during the year; this may explain the variability of astaxanthin concentration that may blur differences between sites and seasons.

\section{LITERATURE CITED}

Browman HI, Rodriguez CA, Béland F, Cullen JJ and 7 others (2000) Impact of ultraviolet radiation on marine crustacean zooplankton and ichthyoplankton: a synthesis of results from the estuary and Gulf of St Lawrence, Canada. Mar Ecol Prog Ser 199:293-311

Chalker-Scott L (1995) Survival and sex ratios of the intertidal copepod, T. californicus, following ultraviolet-B (290-320) radiation exposure. Mar Biol 123:799-804

Davenport J, Barnett PRO, McAllen RJ (1997) Environmental tolerances of three species of the harpacticoid copepod genus Tigriopus. J Mar Biol Assoc UK 77:3-16

Dethier MN (1980) Tidepools as refuges: predation and the limits of the harpacticoid copepod Tigriopus californicus (Baker). J Exp Mar Biol Ecol 42:99-112

Finney DJ (1971) Probit analysis, 3rd edn. Cambridge University Press, Cambridge

Goodwin TW, Srisukh S (1949) Some observations on astaxanthin distribution in marine crustacea. Biochem $\mathrm{J} 45$ : $268-270$

Gorton HL, Williams WE, Vogelmann TC (2001) The light environment and cellular optics of the snow alga Chlamydomonas nivalis (Bauer) Wille. Photochem Photobiol 73: $611-620$

Hairston Jr NG (1979) The adaptive significance of colour polymorphism in two species of Diaptomus (Copepoda). Limnol Oceanogr 24:15-37

Kerr JB, McElroy CT (1993) Evidence for large upward trends of ultraviolet-B radiation linked to ozone depletion. Science 262:1032-1034

Lawlor SM, O'Brien NM (1995) Astaxanthin: antioxidant effects in chicken embryo fibroblasts. Nutr Res 15: 1695-1704

McAllen RJ (1998) Life at its limits: the ecophysiology of the high shore rockpool inhabitant Tigriopus brevicornis. PhD 
thesis, University of London

Miki W (1991) Biological functions and activities of animal carotenoids. Pure Appl Chem 63:141-146

Palozza P, Krinsky NI (1992) Astaxanthin and canthaxanthin are potent antioxidants in a membrane model. Arch Biochem Biophys 297:291-295

Pouzand C, Tyrell RM (1999) Apoptosis, the role of oxidative stress and the example of solar radiation. Photochem Photobiol 70:380-390

Terao J (1989) Antioxidant activity of beta-carotene-related

Editorial responsibility: Otto Kinne (Editor),

Oldendorf/Luhe, Germany carotenoids in solution. Lipids 24:659-661

Tso MOM, Lam TT (1996) Method of retarding and ameliorating central nervous system and eye damage. US Patent \#5527533, Washington, DC

Underwood AJ (1997) Experiments in ecology. Cambridge University Press, Cambridge

Zagarese HE, Feldman M, Williamson CE (1997) UV-Binduced damage and photoreactivation in 3 species of Boeckella (Copepoda, Calanoida). J Plankton Res 19: 357-377

Submitted: December 7, 2001; Accepted: June 8, 2004 Proofs received from author(s): July 23, 2004 